M, Puchrowicz-Ochocki S, O'Neill WW. A comparison of immediate angioplasty with thrombolytic therapy for acute myocardial infarction. N Engl J Med 1993;328:673-9.

28. Zijlstra F, de Boer MJ, Hoorntje JCA, Reiffers S, Reiber JHC, Suryapranata $\mathrm{H}$. A comparison of immediate coronary angioplasty with intravenous streptokinase in acute myocardial infarction. N Engl J Med 1993;328:680-4
29. The GUSTO Angiographic Investigators. The effects of tissue plasminogen activator, streptokinase, or both on coronary-artery patency, ventricular function, and survival after acute myocardial infarction. N Engl J Med 1993;329:1615-22.

30. Navin TR, Hager WD. Creatine kinase MB isoenzyme in the evaluation of myocardial infarction. Curr Probl Cardiol 1979;3:1-32.

\title{
Angiographic, ultrasonic, and angioscopic assessment of the coronary artery wall and lumen area configuration after directional atherectomy: The mechanism revisited
}

\author{
Victor A. Umans, MD, Jose Baptista, MD, Carlo di Mario, $\mathrm{MD}, \mathrm{PhD}$, Clemens von Birgelen, MD, \\ Pascal Quaedvlieg, Pim J. de Feyter, MD, PhD, and Patrick W. Serruys, MD, PhD \\ Rotterdam, The Netherlands
}

The purpose of the present study was to use the complementary information of angiography, intravascular ultrasound, and intracoronary angioscopy before and after directional atherectomy to characterize the postatherectomy appearance of vessel wall contours and the mechanism of lumen enlargement. Directional coronary atherectomy aims at debulking rather than dilating a coronary artery lesion. The selective removal of the plaque may potentially minimize the vessel wall damage and lead to subsequent better late outcome. Whether plaque removal is the main mechanism of action has only to be assessed indirectly by angiography and warrants further investigation with detailed analysis of luminal changes and vessel wall damage by ultrasound and direct visualization with angioscopy. Twenty-six patients have been investigated by quantitative angiography, intravascular ultrasound, and intracoronary angioscopy $(n=19)$ before and after atherectomy. In addition, all retrieved specimens were microscopically examined. Ultrasound imaging showed an increase in lumen area from $1.95 \pm 0.70 \mathrm{~mm}^{2}$ to $7.86 \pm 2.16 \mathrm{~mm}^{2}$ at atherectomy. The achieved gain mainly resulted from plaque removal because plaque plus media area decreased from $18.16 \pm 4.47 \mathrm{~mm}^{2}$ to $13.13 \pm 3.10 \mathrm{~mm}^{2}$. Vessel wall stretching (i.e., change in external elastic lamina area) accounted for only $15 \%$ of lumen area gain. Luminal gain was higher in noncalcified $\left(6.52 \pm 2.12 \mathrm{~mm}^{2}\right)$ lesions than in lesions containing deeply located calcium $\left(5.19 \pm 0.99 \mathrm{~mm}^{2}\right)$ and lowest in superficially calcified lesions $\left(5.41 \pm \mathbf{2 . 4 1} \mathrm{mm}^{2}\right)$. Ultrasound imaging

From the Catheterization Laboratory, Thoraxcenter, University Hospital Dijkzigt, Erasmus University

Received for publication Dec. 7, 1994; accepted Jan. 25, 1995.

Reprint requests: Patrick W. Serruys, MD, PhD, Catheterization Laboratory, Thoraxcenter, Erasmus University, P.O. Box 1738, 3000 DR Rotterdam, The Netherlands.

Copyright $(1) 1995$ by Mosby-Year Book, Inc.

0002-8703/95/\$3.00+0 $\quad 4 / 1 / 64231$ identified an atherectomy byte in $85 \%$ of the cases, whereas angioscopy revealed such a crevice in $74 \%$. The complementary use of the three techniques revealed an underestimation of the presence of dissection/tear and new thrombus by angiography $(10 \%$ and $4 \%)$ and ultrasound imaging $(12 \%$ and $0 \%$ ) compared with angioscopy (26\% and $21 \%$ ). The combined use of angiography, ultrasound, and angioscopy reveals that the postatherectomy luminal lining is not as regular and smooth as that seen by angiography. Luminal enlargement with atherectomy is achieved by plaque excision rather than arterial expansion. (AM HEART J 1995; 130:21727.)

Directional coronary atherectomy has been introduced as an alternative interventional technique aimed at debulking rather than dispersing the protruding coronary artery plaque. ${ }^{1-13}$ The selective removal of the plaque may potentially minimize the vessel wall damage by avoiding the induction of large dissections and promoting the restoration of a large regular vessel lumen. The potential mechanisms responsible for the luminal improvement achieved by directional atherectomy may include (1) plaque removal, (2) vessel wall stretching, (3) creation of dissections, (4) normal vessel wall cutting, (5) plaque redistribution, and (6) plaque compression. Some of these features of directional atherectomy have been assessed in a limited number of angiographic and ultrasound studies, but a comprehensive appreciation of all mechanisms involved in luminal gain after atherectomy has so far not been performed. The introduction of intracoronary ultrasound imaging and coronary angioscopy in clinical practice permits 
Table IA. Patient characteristics

\begin{tabular}{lc}
\hline \multicolumn{1}{c}{ Age (yr) } & $57 \pm 9$ \\
\hline Male/Female & $22 / 4$ \\
Unstable angina & 14 \\
Previous infarction & 4 \\
Previous PTCA & 1 \\
Lesion location & 17 \\
LAD & 6 \\
RCA & 3 \\
LCX & \\
AHA/ACC classification & $3(12 \%)$ \\
Type A & $21(88 \%)$ \\
Type B & $0(0 \%)$ \\
Type C & \\
\hline
\end{tabular}

PTCA, Percutaneous transluminal coronary angioplasty; $L A D$, left anterior descending coronary artery; $R C A$, right coronary artery; $L C X$, left circumflex artery; AHA/ACC, American Heart Association/American College of Cardiology.

Table IB. Lesion characteristics

\begin{tabular}{lccc}
\hline & Angiography & Ultrasound & Angioscopy \\
\hline Eccentric & $22(85 \%)$ & $20(77 \%)^{*}$ & $\dagger$ \\
Calcification & $0(0 \%)$ & $14(55 \%)$ & $\dagger$ \\
Thrombus & $0(0 \%)$ & $0(0 \%)$ & $7(37 \%)$ \\
\hline
\end{tabular}

*Eccentricity index $\leq 0.5$, defined as minimal luminal diameter/maximal luminal diameter.

$\dagger$ No value.

detailed analysis of coronary artery lesion morphologic features and vessel wall damage in a manner not available with angiography. ${ }^{14-24}$ In theory, the combined use of these three imaging techniques may provide insights into the working action of directional coronary atherectomy and may identify factors determining acute success and late outcome. The purpose of this study, therefore, is to use the complementary information of these imaging techniques to describe the vessel wall changes and lumen area configuration after directional atherectomy to elucidate the mechanism of atherectomy.

\section{METHODS}

Patients. The study group comprised 26 patients who underwent directional atherectomy for symptomatic native coronary artery disease (Table IA). The 22 men and 4 women had a mean age of $57 \pm 9$ years. Fifty-four percent of the patients were treated for unstable angina according to the Braunwald. ${ }^{25}$ Four patients had a history of a myocardial infarction and one patient was treated for restenosis after a previous balloon dilatation. Sixty-five percent of the lesions were located in the left anterior descending coronary artery. Directional atherectomy was performed as previously described. ${ }^{6,7}$ All patients had a successful procedure, defined as an angiographic residual diameter stenosis of $<50 \%$ on visual inspection. On-line quantitative coronary angiography (DCI Philips, Eindhoven, The Netherlands) before and after the atherectomy was performed to optimize device selection and to assess the procedural result.

Intracoronary ultrasound imaging. All patients underwent ultrasound imaging before and after atherectomy. The ultrasound images were obtained with a $4.3 \mathrm{~F}, 30 \mathrm{MHz}$ ultrasound catheter (Cardiovascular Imaging Systems Inc., Sunnyvale, Calif.). The catheter was guided by simultaneous fluoroscopic monitoring. Ultrasound gain settings were adjusted for optimal visualization of the arterial wall-lumen interface in normal segments, and saline injections were performed to improve the delineation of the leading-edge echo when necessary. The pullback procedure was started from a side branch visible with both ultrasound and angiography to facilitate identification of the same ultrasonic cross-section within the treated segment.

Qualitative assessment of the ultrasound images was performed by a consensus of three observers who used the integrated information acquired from a pullback maneuver ${ }^{26-28}$ and comprised (1) plaque composition, (2) plaque topography, (3) the presence or absence of dissections, and (4) the presence or absence of an atherectomy byte. A lesion was judged as concentric when a thickening was circumferential along the entire vessel wall and judged as eccentric when a part of the vessel wall was disease free (Table IB). The following definitions were used to describe plaque morphologic features: soft plaques, $<75 \%$ of the plaque area is composed of thickened intimal echoes, with echodensity less than the reference adventitia; fibrous plaques, $<75 \%$ of the plaque area is composed of bright echoes, as bright or brighter than the reference adventitia but without acoustic shadowing; diffuse calcific plaques, bright echoes within a plaque with acoustic shadowing and occupying more than 180 degrees of vessel wall circumference; mixed plaques, a combination of different types. The following definition was used to assess the presence of a dissection: a demarcated break in the linear continuity of the plaque with circumferential or longitudinal involvement of the internal elastic membrane. An atherectomy byte was defined as a rectangular excision into the (sub)intimal layer. Quantitative measurements were made off-line from a videotape. Lumen area was defined as the area within the leading edge echo; external elastic membrane area, the area within the media-adventitia boundary; plaque plus media area, the difference between external elastic membrane area and luminal area. ${ }^{27}$ Variability measurements, including interobserver variability and the correlation between ultrasound measurements with circular phantoms and human coronary artery casts, have been reported previously. ${ }^{29}$

Coronary angioscopy. In 19 patients the target artery was also evaluated by coronary angioscopy before and after atherectomy as previously described. ${ }^{19,}, 30,31$ Unsuitable lesions for angioscopy included (1) proximal stenosis 
location ( $<1.5 \mathrm{~cm}$ from the left main ostium) not allowing effective balloon inflation and (2) excessive tortuosity not allowing visualization of the lumen. Angioscopy was performed with a $4.5 \mathrm{~F}$ angioscope (Baxter-Edwards, Irvine, Calif.). During angioscopy the distal artery was flushed with Ringer lactate solution injected with a flow of 30 to 40 $\mathrm{ml} / \mathrm{min}$. To facilitate the review process, a real-time fluoroscopy or cineangiography was combined with real-time angioscopy and ultrasound imaging by using split-screen videotaping.

Angioscopic images were assessed according to the recommendations of the European Working Group of Angioscopy $^{31}$ : red thrombus was defined as lining or mural thrombus when a red, predominantly mural, nonmobile, superficial mass adherent to the vessel surface was observed, as protruding when a red, intimal protruding, mobile or nonmobile mass adhered to the vessel wall was seen, and as occlusive thrombus when a red intraluminal mass occluded completely the lumen. Dissections were distinguished into small surface disruptions (small, very mobile structures that are contiguous with the vessel wall) and large dissections (visible cracks or fissures on the luminal surface and/or large mobile or nonmobile structures that are contiguous with the vessel wall and of homogeneous appearance with the vessel wall). An atherectomy-induced byte was defined as deep rectangular crevices extending into the wall in conjunction with a mobile flap.

Quantitative coronary angiography. Quantitative analysis of the coronary segments was performed with the computer-based Coronary Angiography Analysis System, which has previously been described in detail. , $^{\text {7, 32-37 In }}$ essence, boundaries of a selected coronary artery segment are detected automatically from optically magnified and video-digitized regions of interest ( $512 \times 512$ pixels) of a cine frame. The absolute diameter of the stenosis in millimeters is determined by using the guiding catheter. The computer estimation of the original dimension of the artery at the site of the obstruction allows definition of interpolated reference diameter. The percentage diameter stenosis is then calculated. To determine the changes in minimal cross-sectional area of the coronary artery segment from the density profile within the artery, videodensitometric algorithm was applied. Calibration of the densitometric area values is accomplished by comparing the reference area calculated from the diameter measurements (assuming a circular cross-section) with the corresponding densitometric area value. Intracoronary isosorbide dinitrate ( 1 to $3 \mathrm{mg}$ ) was given before and after atherectomy. At follow-up catheterization the administration of intracoronary nitrates was recommended before angiography. To standardize the method of data acquisition and data analysis and to ensure reproducibility of postatherectomy and follow-up angiograms, measures were taken as previously described. ${ }^{34-36}$

Histologic analysis. The paraffin-embedded specimens were stained with hematoxylin-azophloxine as a routine stain. Von Kossa's stain was used for calcium. The defini- tions of intima, media, and adventitia have been described previously $y^{38}$ and are in accordance with the recommendations of the American Heart Association Medical/Scientific Statement. ${ }^{39}$

Statistics. All values are expressed as mean $\pm \mathrm{SD}$. The paired Student $t$ test was used to detect differences between continuous variables. Differences between categoric variables were tested with the chi-squared and Fisher exact tests as appropriate. Differences were considered statistically significant where the $p$ value was $<0.05$.

\section{RESULTS}

Lesion morphologic features. On angiography $88 \%$ of the culprit lesions were considered type B lesions according to the American Heart Association/American College of Cardiology classification, $85 \%$ of the lesions were eccentric. None of the lesions were calcified or showed angiographic signs of thrombus (discrete filling defect surrounded by contrast in the absence of calcifications or persistent contrast staining in the area of the stenosis).

The intravascular ultrasound catheter could be advanced through the stenosis in all 26 cases. In 18 patients the ultrasound probe was wedged into the stenosis. Fifty-eight percent of the lesions was characterized as soft lesions with minimal calcific depositions. One lesion was diffusely calcified with a calcific arch of $<180$ degrees whereas lesions in $10(38 \%)$ patients exhibited focal calcifications either superficially $(n=5)$ or deeply located $(n=5)$.

Direct visualization of the vessel wall by angioscopy before atherectomy was performed in 19 patients and showed an irregular lesion in 12 patients. Yellow plaques were seen in 14 patients. Red masses suggestive of thrombus were noted in 8 patients ( 3 protruding and 5 lining thrombi), although this finding was confirmed by histologic evaluation in only 1 of the 6 cases from which material was available for histologic evaluation. No flaps or dissections were observed.

Procedural results. All 26 patients had successful atherectomy procedures that reduced the residual diameter stenosis to $<50 \%$. No balloon predilatation was performed. Atherectomy was performed with a $7 \mathrm{~F}$ atherotome in $84 \%$ of the cases, and a mean of $8 \pm 3$ cuts were made in multiple directions. Although all atherectomy procedures were judged successful on angiography, four patients underwent an adjunctive balloon dilatation to optimize the final result. No major clinical complications (i.e., death, Q-wave myocardial infarction, and coronary artery bypass surgery) were observed. In one patient a non- $Q$ wave infarction (maximum creatine phospho- 
Table II. Quantitative angiographic and ultrasonic measurements of lesion severity and procedural result after directional coronary atherectomy

\begin{tabular}{lccc}
\hline & Preatherectomy & Postatherectomy & $p$ Value \\
\hline Angiography & & & \\
Reference diameter (mm) & $3.52 \pm 0.52$ & $3.70 \pm 0.59$ & $\mathrm{NS}$ \\
Minimal lumen diameter (mm) & $1.16 \pm 0.43$ & $2.85 \pm 0.62$ & $<0.0001$ \\
Diameter stenosis (\%) & $67 \pm 11$ & $23 \pm 13$ & $<0.001$ \\
Minimal cross-sectional area $\left(\mathrm{mm}^{2}\right)$ & $1.20 \pm 0.87$ & $6.67 \pm 2.70$ & $<0.0001$ \\
Area stenosis (\%) & $88 \pm 8$ & $39 \pm 20$ & $<0.001$ \\
Ultrasound & & & 0.02 \\
External elastic lamina area $\left(\mathrm{mm}^{2}\right)$ & $20.11 \pm 4.43$ & $21.00 \pm 3.91$ & $<0.0001$ \\
Plaque plus media area $\left(\mathrm{mm}^{2}\right)$ & $18.16 \pm 4.47$ & $13.13 \pm 3.10$ & $<0.0001$ \\
Lumen area $\left(\mathrm{mm}^{2}\right)$ & $1.95 \pm 0.70$ & $7.86 \pm 2.16$ & \\
\hline
\end{tabular}

Table III. Ultrasonic assessment of plaque reduction and lumen area gain achieved at atherectomy according its localization and histologic confirmation

\begin{tabular}{|c|c|c|c|}
\hline \multirow[b]{2}{*}{ Ultrasound } & \multicolumn{2}{|c|}{ Histology } & \multirow[b]{2}{*}{ Total } \\
\hline & Calcium & No calcium & \\
\hline \multicolumn{4}{|l|}{ Plaque reduction $\left(\mathrm{mm}^{2}\right)$} \\
\hline Subendothelial calcium & $\begin{array}{c}4.13 \pm 2.11 \\
(n=5)\end{array}$ & $\begin{array}{c}0 \\
(n=0)\end{array}$ & $\begin{aligned} 4.13 & \pm 2.11 \\
(n & =5)\end{aligned}$ \\
\hline Base of plaque calcium & $\begin{array}{c}4.95 \pm 1.36 \\
\quad(n=5)\end{array}$ & $\begin{array}{c}3.85 \pm 1.49 \\
(n=5)\end{array}$ & $\begin{array}{c}4.40 \pm 1.46 \\
(n=10)\end{array}$ \\
\hline No calcium & $\begin{array}{c}6.21 \pm 4.75 \\
(n=5)\end{array}$ & $\begin{array}{c}5.62 \pm 2.26 \\
(n=6)\end{array}$ & $\begin{array}{c}5.89 \pm 3.47 \\
(n=11)\end{array}$ \\
\hline TOTAL & $\begin{array}{c}5.16 \pm 3.16 \\
(n=15)\end{array}$ & $\begin{array}{c}4.88 \pm 2.10 \\
(n=11)\end{array}$ & \\
\hline \multicolumn{4}{|l|}{ Lumen area gain $\left(\mathrm{mm}^{2}\right)$} \\
\hline Subendothelial calcium & $\begin{array}{c}5.41 \pm 2.41 \\
(n=5)\end{array}$ & $\begin{array}{c}0 \\
(n=0)\end{array}$ & $\begin{array}{c}5.41 \pm 2.41 \\
\quad(n=5)\end{array}$ \\
\hline Base of plaque calcium & $\begin{aligned} 5.19 & \pm 0.99 \\
(n & =5)\end{aligned}$ & $\begin{array}{c}5.83 \pm 1.57 \\
(n=5)\end{array}$ & $\begin{array}{c}5.51 \pm 1.28 \\
(n=10)\end{array}$ \\
\hline No calcium & $\begin{array}{c}6.34 \pm 2.72 \\
(n=5)\end{array}$ & $\begin{array}{c}6.68 \pm 1.66 \\
(n=6)\end{array}$ & $\begin{array}{c}6.52 \pm 2.12 \\
(n=11)\end{array}$ \\
\hline TOTAL & $\begin{array}{c}5.69 \pm 2.13 \\
(n=15)\end{array}$ & $\begin{array}{c}6.33 \pm 1.61 \\
(n=11)\end{array}$ & \\
\hline
\end{tabular}

kinase $600 \mathrm{U} / \mathrm{L}$ ) occurred as a result of a guiding catheter-induced occlusive dissection of the right coronary ostium after a successful atherectomy. During coronary angioscopy, the majority of the patients experience chest pain with concomitant electrocardiographic changes, suggestive of ischemia. After balloon deflation, these abnormalities subsided and the chest pain disappeared.

Quantitative angiography (Table II). The mean vessel size of this patient population was $3.52 \pm 0.52$ $\mathrm{mm}$. Atherectomy induced an increase in minimal luminal diameter from $1.16 \pm 0.43 \mathrm{~mm}$ to $2.85 \pm 0.62$ $\mathrm{mm}(p<0.001)$. After atherectomy, the diameter stenosis and area stenosis were $23 \% \pm 13 \%$ and $39 \% \pm 20 \%$, respectively. Correspondingly, the minimal luminal cross-sectional area as derived from videodensitometry also increased from $1.20 \pm 0.87$ $\mathrm{mm}^{2}$ to $6.67 \pm 2.70 \mathrm{~mm}^{2}(p<0.001)$.

Quantitative ultrasound measurements. External elastic membrane area, lumen area, and plaque plus media area at the normal reference segment proximal to the stenotic lesion did not change significantly during the procedure. No difference in external elastic membrane area between the reference and stenotic segment $\left(20.94 \pm 5.39 \mathrm{~mm}^{2}\right.$ vs $20.11 \pm 4.43$ $\mathrm{mm}^{2} ; p$ value not significant [NS]) was found, in other words no compensatory enlargement at the site of the stenosis could be documented. Directional atherectomy induced a significant increase in lumen area from $1.95 \pm 0.70 \mathrm{~mm}^{2}$ to $7.86 \pm 2.16 \mathrm{~mm}^{2}(p<$ 0.0001 ) and a decrease in plaque plus media area from $18.16 \pm 4.47 \mathrm{~mm}^{2}$ to $13.13 \pm 3.10 \mathrm{~mm}^{2}$ 


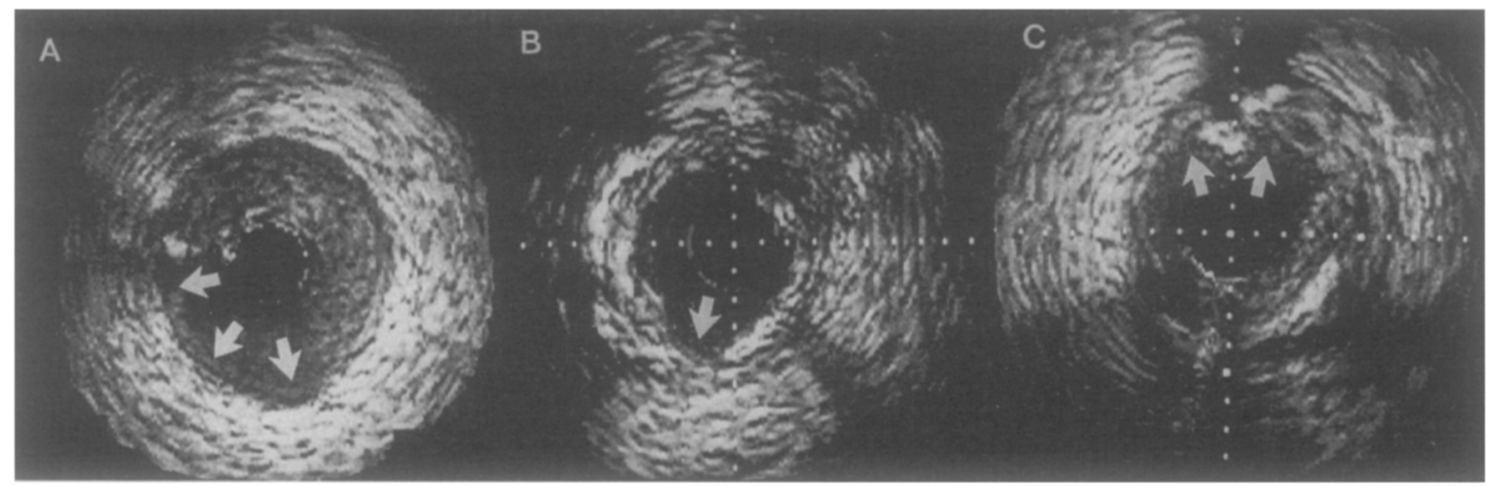

Fig. 1. Intracoronary ultrasonic images of three patients illustrate patterns of atherectomy bytes (arrows). A, Multiple bytes were performed in normal vessel wall opposite to atherosclerotic plaque. B, Single atherectomy byte next to treated lesion shows deposits of deep calcifications. C, Pattern of two atherectomy bytes with remaining part of calcified plaque between both bytes. Apparently, atherotome was unable to remove this piece of calcification.

$(p<0.0001)$. The external elastic membrane area changed from $20.11 \pm 4.43 \mathrm{~mm}^{2}$ to $21.00 \pm 3.91 \mathrm{~mm}^{2}$ $(p=0.02)$, which implies that vessel wall stretching is responsible for only $15 \%$ of the lumen area improvement achieved at directional atherectomy. The gain in lumen area was not dependent on lesion morphologic features $\left(6.33 \pm 2.05 \mathrm{~mm}^{2}\right.$ vs $5.49 \pm$ $1.68 \mathrm{~mm}^{2} ; p=0.30$ soft vs mixed lesions) but did differ between calcified and noncalcified lesions; the change in lumen area varied with the location of calcium and was lowest in lesions that contained (superficial) subendothelial calcium as compared to (deep) calcium at the base of the plaque (5.41 \pm 2.41 $\mathrm{mm}^{2}$ vs $5.51 \pm 2.41 \mathrm{~mm}^{2}$ ). Plaque reduction in crosssectional lumen area was greatest in ultrasonic noncalcified lesions when compared with calcified lesions $\left(5.89 \pm 3.47 \mathrm{~mm}^{2}\right.$ vs $\left.4.13 \pm 2.11 \mathrm{~mm}^{2}\right)$. There were too few patients with three or four quadrant calcifications to assess the influence of the calcification arc on area improvement. Subsequent histologic examination confirmed the presence of calcium in all plaques containing ultrasound evidence of superficial calcium $(n=5)$, whereas the presence of calcium was confirmed in $50 \%$ of cases with deep calcium $(n=10)$. In addition, plaque reduction and lumen area gain were higher in those cases with histologic evidence of calcium than those without calcium in the retrieved specimen (Table III).

The postatherectomy lumen area configuration (Figs. 1 through 4). Angiography after atherectomy revealed a smooth luminal lining in 19 patients, persistent haziness in 4 , a dissection in 2 , and thrombus in 1. Ultrasound imaging showed a regular lumen configuration in $4(15 \%)$ of the 26 patients, an irregular configuration in $15(40 \%)$, a subintimal tear in $4(15 \%)$, and a dissection in $3(12 \%)$. The appearance of a tear or dissection was not related and did not apparently contribute to lumen area gain as assessed by ultrasound because the gain in lumen area was not different in this group compared with patients without evidence of dissections/tears $\left(5.81 \pm 2.82 \mathrm{~mm}^{2}\right.$ vs $\left.5.95 \pm 1.68 \mathrm{~mm}^{2} ; p=\mathrm{NS}\right)$.

In $22(85 \%)$ patients evidence of atherectomy bytes resulted in a noncircular lumen area configuration. A cloverlike postatherectomy area configuration was never observed. Although the atherotome was directed toward the plaque in one patient, the atherectomy bytes were made into the nondiseased area next to the plaque with proven deep-tissue resection. In 11 patients with histologically proven deep-tissue resection, ultrasound imaging showed an atherectomy byte in 4 patients and a dissection in an additional 2 patients. Coronary angioscopy revealed an intracoronary thrombus after atherectomy in 11 $(61 \%)$ patients. In $4(21 \%)$ of these patients this was a new thrombus, whereas in the remaining 7 patients thrombus was already observed before atherectomy. Dissections were observed in $5(26 \%)$ patients and multiple or single subintimal flaps were seen in $9(42 \%)$ and $2(11 \%)$ patients, respectively. In 14 (74\%) patients a crevice suggestive of an atherectomy byte was observed (Fig. 3).

Complementary information of the three imaging techniques. Fig. 5 shows the frequency of dissections and thrombi detected by angiography, ultrasound, and angioscopy. Angiography definitely underestimates the incidence of dissections (10\%) compared with ultrasound $(12 \%)$ and angioscopy $(26 \%)$. The dissection seen on angiography was also detected by ultrasound and angioscopy; however, angiography detected only 


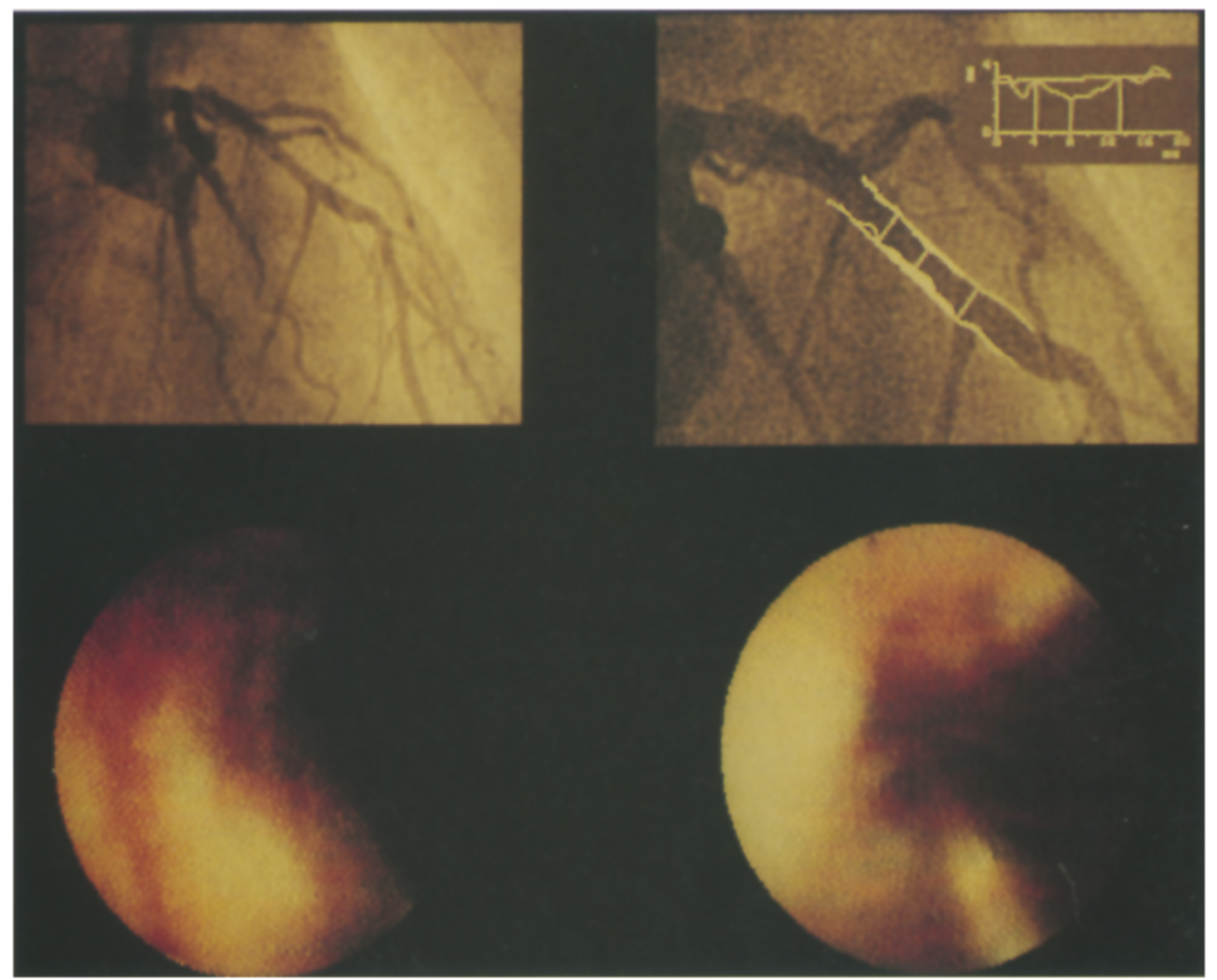

Fig. 2. Angiographic and angioscopic observations of atherectomized stenosis in mid portion of left anterior descending coronary artery. After atherectomy, coronary artery wall had smooth contour (top left), whereas on-line quantitative coronary angiography shows mild residual stenosis (top right). On angioscopy, proximal part of artery had indeed smooth wall configuration (bottom right), however, opposed to angiographic findings, small flap and crevice suggestive of atherectomy cut at target lesion were seen (bottom left).

$33 \%$ of the dissections observed by ultrasound and $9 \%$ of the small and $0 \%$ of the big dissections noted by angioscopy. Although none of the big dissections visualized by angioscopy were demonstrated by ultrasound, all of these patients had an irregular luminal contour on ultrasound examination. The incidence of postatherectomy thrombus detected by angioscopy was $58 \%$ compared to $0 \%$ and $4 \%$ by ultrasound and angiography.

Histologic evaluation. On macroscopic examination, the appearance of the removed specimens was variable, ranging from translucent strips of white tissue to yellow tissue with brown areas indicative of thrombus. Histopathologic information on retrieved tissue was available in $24(92 \%)$ cases. Evidence of media or internal elastic lamina, indicating that resection of deep vessel wall layers had occurred, was observed in $11(46 \%)$ cases. Three of those also contained evidence of adventitia. Thrombus was identified in $16(67 \%)$ samples. A conclusive differentiation between intraplaque hemorrhage and mural throm- bus could not be ascertained given the fragmented nature of atherectomy specimens and the lack of spatial landmarks. Various degrees of organization were found in $50 \%$ of the thrombotic specimens. Other histologic findings included the presence of neointimal hyperplasia in $6(25 \%)$ lesions. Atherosclerotic plaque was found in $21(88 \%)$ specimens, with $14(54 \%)$ of them showing calcium deposits.

\section{DISCUSSION}

Because intracoronary ultrasound imaging and coronary angioscopy permit detailed analysis of coronary artery lesion morphologic features and vessel wall damage in a manner not available with angiography, the complementary information obtained with these three imaging techniques is of pivotal value for the assessment of the mechanisms of luminal improvement during directional coronary atherectomy. The major findings of this study are threefold. First, the present study demonstrates that the combined use of quantitative angiography, coronary ultra- 
sound imaging, and intracoronary angioscopy may be applied safely in patients who underwent atherectomy for stable and unstable angina. Second, the main mechanism of action of atherectomy appears to be plaque reduction by excision rather than vessel wall stretching. Although selective plaque removal should in theory lead to a circular vessel lumen, ultrasound imaging in this series detected atherectomy bytes outside the plaque area and nonconfluent bytes in the plaque. Subsequent direct visualization by angioscopy confirmed these bytes as vessel wall trenches. Therefore, the postatherectomy vessel wall configuration is not circular or smooth as previously demonstrated in angiographic observations. ${ }^{3}$ Whether this irregularity ultimately may facilitate the renarrowing process by allowing ingrowth of hyperplastic tissue within these areas remains to be assessed. Third, unlike the angiographic observations, detailed angioscopic imaging showed evidence of substantial vessel wall trauma leading to an irregular postatherectomy lumen configuration with dissections, bytes, and thrombi.

Plaque reduction. The present study offers more detailed information on the mechanism of plaque reduction because, unlike in other studies, all lesions were crossed by the ultrasound device before and after atherectomy. Subsequently, plaque reduction was found to be the major determinant of the final luminal improvement achieved by atherectomy. These findings concur with those of other groups ${ }^{22-24}$ and clearly differ from those of balloon angioplasty studies. These differences in action of devices may be of importance when examining the long-term results of various interventions. The present observations indicate that, as a result of differences in luminal improvement, the renarrowing process after atherectomy may be of another nature (i.e., hyperplasia) than after balloon dilatation (i.e., recoil).

Vessel wall stretching. Our observations indicate that although a significant plaque reduction occurred in most cases, accounting for most of the luminal gain, vessel wall stretching was the mechanism of luminal enlargement in some individual cases. In the entire group, vessel wall stretching (defined as the difference in external elastic membrane area before and after atherectomy) was found to be a major contributor in the lumen area increase which is opposed to findings in a previous angiographic study. ${ }^{13}$ However, it should be acknowledged that the relative contribution of vessel expansion to the overall enlargement in lumen might have been greater if adjunctive balloon dilatation had been performed more frequently.

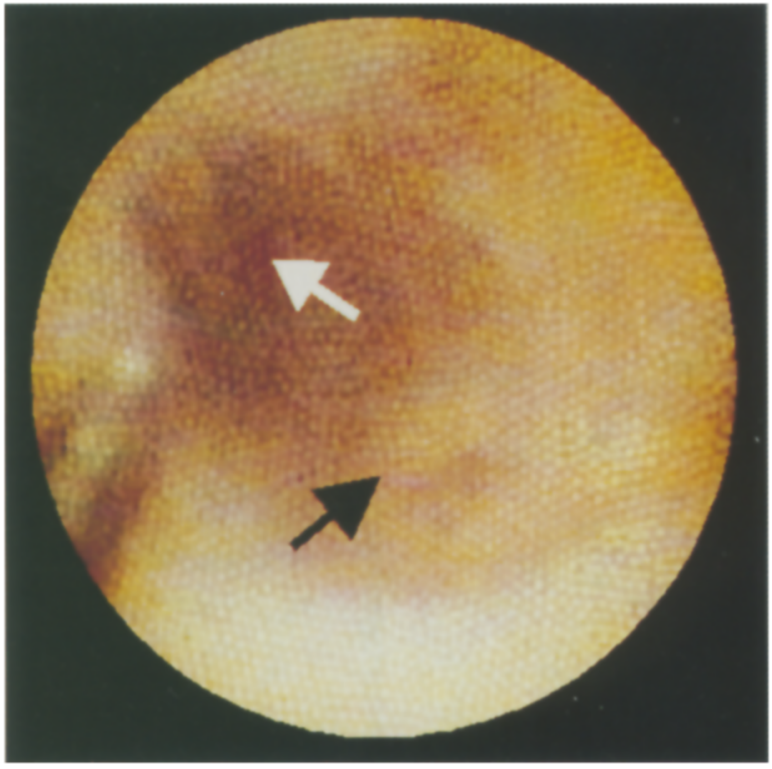

Fig. 3. Angioscopic illustration of vessel wall configuration after directional atherectomy. White arrow indicates site of excision, which has formed crevice into wall. Small flap is observed at site of residual lesion (black arrow). Residual lesion contains yellow plaque material and has irregular surface.

Normal wall retrieval. Disease-free wall excision, which is unique to directional atherectomy, indeed plays a role in the mechanism of lumen area enlargement. In the present patient population, ultrasound was the only technique that could determine whether the atherectomy bytes were appropriately targeted. Until now, this feature of directional atherectomy has not been highlighted, with the exception of a case report on the death of a patient as a result of coronary artery rupture. ${ }^{40}$ There are two possible explanations for the occurrence of inappropriate directional cutting. First, device positioning was achieved under fluoroscopic guidance yielding a two-dimensional representation of the arterial geometry. Subsequent inappropriate positioning may well occur and not be visualized by angiography. Second, device rotation during cutting may have happened as a result of lesion characteristics or device under sizing or oversizing. In our series, no stenosis characteristics were found to be predictive of the occurrence of disease-free vessel wall cutting, and adequate device sizing was performed by using digital quantitative angiography to estimate vessel size and lesion severity. In the cases with predominant disease-free wall oriented shaving, angiography showed a small residual stenosis after atherectomy and is thus of limited value in determining the 


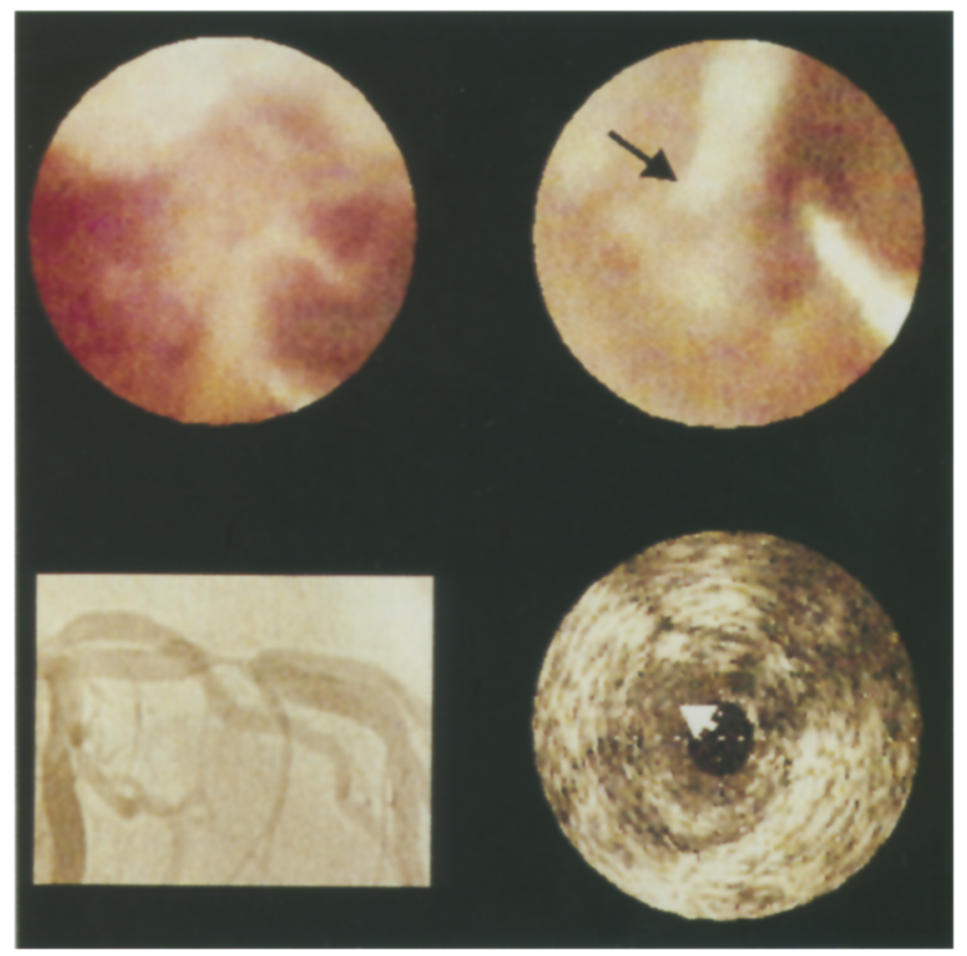

Fig. 4. Combined use of angiography, ultrasound imaging, and angioscopy in patient who underwent directional atherectomy. Top left, Concomitant angiographic view and concentric lesion without evidence of thrombus. Top right, Enlarged lumen as assessed by ultrasound and orientation of atherectomy byte (arrow). Bottom left, Angioscopic view of target stenosis before atherectomy with thrombus present. Bottom right, Angioscopy after atherectomy identified increase in lumen, protruding flap without evidence of thrombus (arrow).

postprocedural lumen area geometry. Additional passages with the atherotome to remove the plaque under angiographic guidance may in these cases be hazardous, and our observations call for the urgent need of ultrasound-guided atherectomy to avoid this complication.

Compression and remodeling. Whether the amount of plaque reduction represents tissue removal rather than redistribution cannot be elucidated from this study because three-dimensional reconstruction of the stenosis was not performed routinely.

Dissections. In a previous angiographic study, Hinohara et al. ${ }^{41}$ concluded that atherectomy resulted in a smooth vessel wall contour with less dissections than after balloon angioplasty. The present study offers the benefit of using the complementary information obtained by ultrasound and angioscopy and shows that these two imaging techniques more accurately detect dissections and irregular wall abnormalities. These findings are in agreement with observations of the GUIDE I trial, in which dissections were seen in $40 \%$ by ultrasound and in $19 \%$ by angiography. ${ }^{42}$ In concert with these observations, the combined use of two imaging modalities may provide further insights into the origin of dissections. Indeed, our study indicates that dissections may be the result of the specific cutting mechanism of atherectomy because the dissections were located at the site of the atherectomy bytes as visualized by angioscopy. Tenaglia et al ${ }^{43}$ demonstrated the clinical significance of these observations and found that patients with an adverse outcome after atherectomy had a significant higher incidence of dissections compared to patients without adverse events. In keeping with these findings, we performed addition balloon dilatation after postatherectomy ultrasound assessment in two patients to improve the atherectomy result, thereby avoiding the risk of adverse events. The absence of such events in this population may reflect the advantage of such ultrasound guided atherectomy procedures.

Thrombus. The detection of intracoronary thrombus by angiography has been hampered by the low resolution of the image intensifiers. Therefore it is understandable that direct visualization of the coronary vessel wall by angioscopy proved to be more ac- 
curate to identify thrombi than angiography. ${ }^{17,44-46}$ Again like dissections, the clinical significance of postatherectomy thrombi resides in the high acute event rate associated with this finding, ${ }^{47}$ and therefore the prevention or treatment of postatherectomy thrombi may beneficially influence short-term outcome and late outcome after atherectomy. In particular, thrombi resection has been associated with less restenosis, ${ }^{48,49}$ whereas residual intraluminal thrombus is a potential stimulus for an augmented proliferative vessel wall response. Although angioscopy revealed postatherectomy thrombi in $33 \%$ of the present patients, no acute events were seen. Whether subsequent intervention (thrombolysis, angioplasty) after the detection of thrombi results in a decrease in the restenosis rate remains to be determined.

Atherectomy for calcified lesions. Although angiography did not detect the presence of calcium in any of the atherectomized lesions, 10 lesions contained focal deposits of calcium as demonstrated by ultrasound and 14 were calcified according to histologic definitions. Although no statistical differences were detected in quantitative ultrasound measurements before and after directional atherectomy, a trend toward less plaque reduction and lumen area gain was observed in calcified lesions. More specifically, the localization of the calcium appears to be a determinant of the acute procedural result of atherectomy, with less gain in those plaques with superficially located subendothelial calcium. Apparently, the cutting mechanism is less effective when the atherotome has to cut through areas containing calcium. The combined use of intravascular ultrasound and histologic evaluation also provides evidence that directional atherectomy removes calcium. Specifically, all lesions that contained superficially located spots of calcium had histologic evidence of calcium in their atherectomy specimens, whereas only $50 \%$ of the deeply situated calcium could be retrieved. Because of acoustic shadowing of the calcium, the thickness of the calcium spots cannot be measured and therefore the amount of calcium removed cannot be determined. These results suggest that microcalcification of coronary artery lesions does not play a negative role when performing directional atherectomy.

Postatherectomy lumen area configuration. Luminal renarrowing is a problem that is equally as vexing after new interventions than after conventional balloon angioplasty. Recent publications on long-term results after interventions with new devices such as stenting and atherectomy have taught us that the acute procedural result partially determines the late angiographic outcome..$^{1,4,5,7-10}$ However, even when an optimal angiographic procedural result after

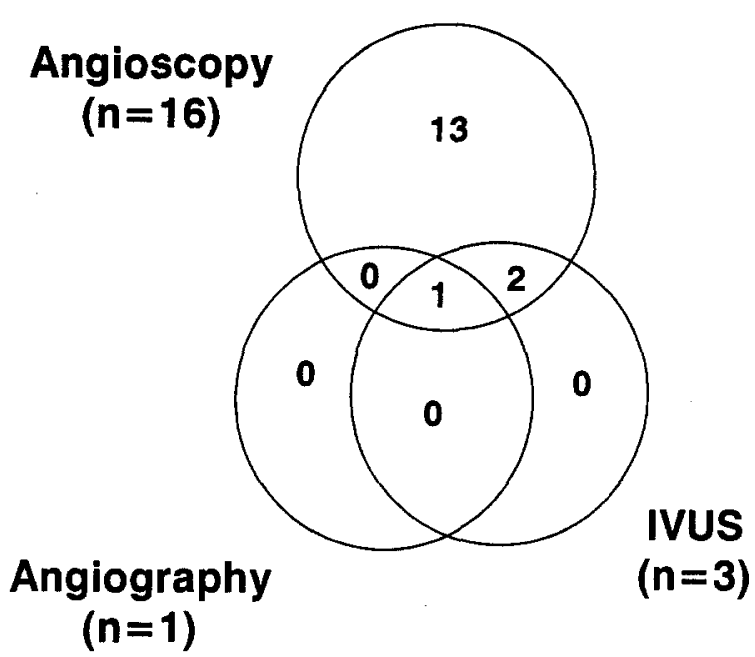

Fig. 5. Venn diagram illustrates complementary information obtained by angiography, intracoronary ultrasound imaging, and coronary angioscopy with respect to detection of dissections. As shown, angiography and ultrasound imaging underestimate incidence of dissections as compared with angioscopy.

atherectomy or stenting is obtained, restenosis remains the major limitation of these procedures. ${ }^{1-11,36}$ With the clinical application of ultrasound imaging and angioscopy, more detailed information regarding the effect of the disruptive process of an intracoronary intervention on the luminal geometry can be obtained. In particular, ultrasound imaging has been shown to be superior in detecting dissections than angiography, ${ }^{16,18}$ whereas angioscopy is more efficient in visualizing thrombus. ${ }^{44-46}$ Subsequent analyses of such images may identify predictors for restenosis. Preliminary findings have indeed indicated that vessel wall stretching and tearing may lead to an increased fibroproliferative response. ${ }^{50}$ Also, disruption of the internal elastic lamina leads to an enhanced luminal renarrowing process in human stented venous grafts ${ }^{51}$ and swine-stented coronary arteries. ${ }^{52-54}$

Conclusions. The complementary information of ultrasound imaging and coronary angioscopy have revealed further insight into the mechanism of directional atherectomy. In particular, atherectomy yields a less circular vessel wall area configuration with a higher number of dissections and more residual thrombi than are detected on angiography. These results suggest that ultrasound and/or angioscopy may be used to guide atherectomy procedures, thereby identifying an adverse angiographic outcome that may lead to serious clinical complications.

Limitations. This study has several limitations. First, although at the outset of the study it was fore- 
seen that all patients who underwent atherectomy and had suitable anatomy for intracoronary angioscopy would be included in this prospectively collected series, it was not to perform angioscopy in some patients. Second, the size of the intravascular ultrasound catheter and the guide wire artifact may have led to an underestimation of the number and orientation of the atherectomy bytes. Third, because a motorized pullback procedure with three-dimensional ultrasonic reconstruction was not routinely performed, the extent of compression and remodeling could not be assessed. Fourth, we recognize the relative small sample size of our study population, which precludes further subgroup analyses. However, this pilot study does provide useful information on the working mechanism of atherectomy and the complementary information provided by the three imaging techniques. Finally, although the procedure was occasionally influenced by the ultrasonic and angiocopic information, it was not our intention to examine the impact of these imaging techniques on procedural outcome.

\section{REFERENCES}

1. Safian RD, Gelbfish JS, Erny RE, Schnitt SJ, Schmidt D, Baim DS. Coronary atherectomy: clinical, angiographic and histologic findings and observations regarding potential mechanisms. Circulation 1990; 82:69-79.

2. Popma JJ, De Ceasare NB, Ellis SG, Holmes DR, Pinkerton CA, Whitlow P, King SB, Ghazzal ZMB, Topol EJ, Garratt KN, Kereiakes DJ. Clinical, angiographic and procedural correlates of quantitative coronary dimensions after directional coronary atherectomy. J Am Coll Cardiol 1991;18:1183-91.

3. Hinohara T, Robertson GC, Selmon MR, Vetter JW, Rowe MH, Braden LJ, McAuley BJ, Sheehan DJ, Simpson JB. Restenosis after directional coronary atherectomy. J Am Coll Cardiol 1992;20:623-33.

4. Kuntz RE, Gibson CM, Nobuyoshi M, Baim DS. Generalized model of restenosis after conventional balloon angioplasty, stenting and directional atherectomy. J Am Coll Cardiol 1993;21:15-25.

5. Serruys PW, Umans VAWM, Strauss BH, van den Brand M, Suryapranata H, de Feyter PJ, Roelandt JRTC. Quantitative angiography after directional coronary atherectomy. Br Heart J 1991;66:122-9.

6. Umans VA, Hermans W, Foley DP, Strikwerda S, van den Brand M, de Jaegere P, de Feyter PJ, Serruys PW. Restenosis following directional coronary atherectomy and balloon angioplasty: a comparative analysis based on matched lesions. J Am Coll Cardiol 1993;21:1382-90.

7. Umans VA, Robert A, Foley DP, Haine E, de Feyter PJ, Wijns W, Serruys $P W$. Luminal renarrowing after directional coronary atherectomy: multivariate analysis of long-term outcome and renarrowing process. J Am Coll Cardiol 1994;23:49-59.

8. Topol EJ, Leya F, Pinkerton CA, Whitlow P, Hofling B, Simonton CA, Masden RR, Serruys PW, Leon MB, Williams DO, King SB, Mark DE, Isner JM, Molines DR, Ellis SG, Lee KL, Keeler GP, Berden LG, Himohara T, Califf RM. The coronary angioplasty versus excisional atherectomy trial. N Engl J Med 1992;329:221-7.

9. Adelman AG, Cohen M, Kimball BP, Bonan R, Ricci DR, Webb JG, Laramee L, Barbeau G, Traboulsi M, Corbett BN, Schwartz L, Logan AG. Canadian Coronary Atherectomy Trial. A randomized comparison of directional coronary atherectomy and percutaneous transluminal coronary angioplasty for lesions of the proximal left anterior descending artery. N Engl J Med 1993;329:228-34.

10. Fishman RF, Kuntz RE, Carrozza JP Jr, Miller MJ, Lenerchia CC, Schmidt SJ, Diver DJ, Safia R, Baim DS. Long-term results of direc- tional coronary atherectomy: predictors of restenosis. J Am Coll Cardiol 1992;20:1101-10.

11. Popma JJ, De Cesare NB, Pinkerton CA, Kereiakes DJ, Witlow R, King SB, Topol EJ, Holmes DR, Leon MB, Ellis S. Quantitative analysis of factors influencing late lumen loss and restenosis after directional coronary atherectomy. Am J Cardiol 1993;71:552-7.

12. Penny WF, Schmidt DA, Safian RD, Erny RE, Baim DS. Insights into the mechanism of luminal improvement after directional coronary atherectomy. Am J Cardiol 91;67:435-7.

13. Umans VA, Haine E, Renkin J, de Feyter PJ, Wijns W, Serruys PW. The mechanism of directional coronary atherectomy. Eur Heart J 1993;14:505-10.

14. Tobis JM, Mallery JA, Gessert J. Intravascular ultrasound cross-sectional arterial imaging before and after balloon angioplasty in vitro. Circulation 1989;14:947-52.

15. Potkin BN, Keren G, Mìntz G, Douek PC, Pichard AD, Statlen LF, Kent $\mathrm{KM}$, Leon MB. Arterial response to balloon angioplasty: an intravascular ultrasound study. J Am Coll Cardiol 1992; 20:942-51.

16. Di Mario C, Baptista J, Keane D, Umans V, Herman JPR, de Jaegere P, de Feyter PJ, Roelandt JRTC, Serruys PW. Intracoronary imaging and non-imaging techniques for guidance of coronary interventions. In: Maresta A, Invernizzi R, eds. Advances in interventional cardiology and cardiac surgery [In press].

17. Sherman CT, Litvack F, Forrester J. Coronary angioscopy in patients with unstable and stable angina. N Engl J Med 1986;315:913-9.

18. Siegel RJ, Chae JS, Forrester JS, Ruiz CE. Angiography, angioscopy and ultrasound before and after percutaneous balloon angioplasty. AM HEART J 1990;120:1086-90.

19. Escaned J, di Mario C, Baptista J, Foley D, de Jaegere P, van den Brand $M$, Serruys $P W$. The use of angioscopy in percutaneous coronary interventions. J Intervent Cardiol 1994;7:65-75.

20. Gussenhoven EJ, Essed CE, Lancee CT, Bom N, Roelandt JRTC. Arterial wall characteristics determined by intravascular ultrasound imaging: an in vitro study. J Am Coll Cardiol 1989;14:947-52.

21. Siegel RJ, Ariani M, Fishbein MC, Hogson W. Histopathological validation of angioscopy and intravascular ultrasound. Circulation 1991; 84:109-17.

22. Tenaglia AN, Buller CE, Kisslo KB, Stack RS, Davidson CJ. Mechanism of balloon angioplasty and directional coronary atherectomy as assessed by intravascular ultrasound. J Am Coll Cardiol 1992;20:68591.

23. Leso JS, Romero M, Medina A, Pan M, Pavlovic D, Vaamonde R, Hernandes E, Melian F, Rubio FL, Marrens J, Segura J, Irurita M, Cabrera JA. Intracoronary ultrasound assessment of directional atherectomy: immediate and follow-up findings. J Am Coll Cardiol 1993;21:298-307.

24. Braden GA, Herrington DM, Downes TR, Kutcher MA, Little WC Qualitative and quantitative contrasts in the mechanisms of luminal enlargement by coronary balloon angioplasty and directional coronary atherectomy. J Am Coll Cardiol 1994;23:40-8.

25. Braunwald E. Unstable angina. A classification. Circulation 1989; 80:410-4.

26. Gussenhoven EJ, Essed CE, Frietman P, Bom N, Roelandt JRTC. Intravascular echocardiographic assessment of vessel wall characteristics: a correlation with histology. Int J Cardiac Imaging 1989;4:105-16.

27. Hodgson JM, Reddy KG, Suneja R, Nair RN, Leasnefsky EJ, Sheehan HM. Intracoronary ultrasound imaging: correlation of plaque morphology with angiography, clinical syndrome and procedural results in patients undergoing coronary angioplasty. J Am Coll Cardiol 1993;21:3544.

28. Di Mario C, The SHK, Madrestma S, Serruys PW, Roelandt JRTC. Detection and characterization of vascular lesions by intravascular ultrasound: an in vitro study correlated with histology. J Am Soc Echocardiogr 1992;5:135-46.

29. Haase J, Ozaki Y, Di Mario C, Escaned J, de Feyter PJ, Roelandt JRTC, Serruys PW. Can intracoronary ultrasound correctly assess the luminal dimensions of coronary artery lesions? A comparison with quantitative angiography. Eur Heart J [In press].

30. de Feyter PJ, Escaned J, Baptista J, de Jaegere P, Serruys PW. Ischemia related lesion characteristies in patients with unstable and stable angina: a study with intracoronary angioscopy and ultrasound. Circulation. In press. 
31. den Heijer P, Foley DP, Hillege HL. The Ermenonville classification of observations at coronary angioscopy-evaluation of intra and inter observer agreement. Eur Heart J. In press.

32. Reiber JHC, Serruys PW, Kooijman CJ, de Feyter PJ, van den Brand M, Heyenholtz PG. Assessment of short-, medium-, and long-term variations in arterial dimensions from computer-assisted quantitation of coronary cineangiograms. Circulation 1985;71:280-8.

33. Beatt KJ, Serruys PW, Hugenholtz PG. Restenosis after coronary angioplasty: new standards for clinical studies. J Am Coll Cardiol 1990;15:491-8.

34. Serruys PW, Rutsch W, Heyndrickx GR, Danchin N, Mast G, Wijns W, Rensing BJ, Vos J, Stibbe J. Prevention of restenosis after percutaneous transluminal coronary angioplasty with thromboxane $\mathrm{A}_{2}$ receptor blockade, a randomized, double-blind aspirin-placebo controlled trial. Circulation 1991;84:1568-80.

35. The MERCATOR study group. Does the new angiotensin converting enzyme inhibitor cilazapril prevent restenosis after percutaneous transluminal coronary angioplasty? The results of the MERCATOR study: a multicenter randomized double-blind placebo-controlled trial. Circulation 1992;86:100-10.

36. Serruys PW, Strauss BH, Beatt KJ, Bertrand ME, Puel J, Rickards AF Meier B, Goy JJ, Vogt P, Kappenberger L, Sigward U. Angiographic follow-up after placement of a self-expanding coronary artery stent. $\mathrm{N}$ Engl J Med 1991;1:28-34.

37. Haase J, di Mario C, Slager CJ, van der Giessen WJ, den Boer A, de Feyter PJ, Reiber JHC, Verdouw PD, Serruys PW. In vivo validation of on-line and off-line geometric coronary measurements using insertion of stenosis phantoms in porcine coronary arteries. Cathet Cardiovasc Diagn 1992;27:16-27.

38. Escaned J van Suylen RJ, MacLeod DC, Umans VAWM, de Jong M, Bosman FT, de Feyter PJ, Serruys PW. Histologic characteristics of tissue excised during directional coronary atherectomy in stable and unstable angina pectoris. Am J Cardiol 1993;71:1442-7.

39. Stary HC, Blankenhorn DH, Chandler B, Glagov S, Insull W, Richardson M, Rosenfeld ME, Schaffer SA, Schwartz CJ, Wagner WD, Wissler R. A definition of the intima of human arteries and of its atherosclerotic-prone regions. Circulation 1992;85:391-405.

40. van Suylen RJ, Serruys PW, Simpson JB, de Feyter PJ, Strauss BH Zondervan PE. Delayed rupture of the right coronary artery after directional coronary atherectomy for bail-out. AM HEART J 1991; 121:914-6.

41. Hinohara T, Rowe MH, Robertson GC, Selmon MR, Braden IJ, Vetter JW, Simpson JB. Effect of lesion characteristics on outcome of directional coronary atherectomy. J Am Coll Cardiol 1991;19:1112-20.

42. GUIDE Trial Investigators. Discrepancies between angiographic and intravascular ultrasound appearance of coronary lesions undergoing interventions. A report from phase I of the GUIDE trial [Abstract]. J Am Coll Cardiol 1993;21:118A.

43. Tenaglia AN, Buller CE, Kisslo KB, Phillips HR, Stack RS, Davidson CJ. Intracoronary ultrasound predictors of adverse outcomes after coronary artery interventions. J Am Coll Cardiol 1992;20:1385-91.

44. Ramee SR, White CJ, Collins TJ, et al. Percutaneous angioscopy during coronary angioplasty using a steerable angioscope. J Am Coll Cardiol 1991;17:100-5

45. Mizuno $\mathrm{K}$, Satomura $\mathrm{K}$, Ambrose JA, et al. Angioscopic evaluation of coronary artery thrombi in acute coronary syndromes. N Engl J Med 1992;326:287-91.

46. Den Heijer P, Foley DP, Escaned Barbosa J, Hillige HL, van Dijk RB, Serruys PW, Lie KI. Angioscopic versus angiographic detection of intimal dissection and intracoronary thrombus. J Am Coll Cardiol. In press.

47. Popma JJ, Topol EJ, Hinohara T. Abrupt closure after directional coronary atherectomy: clinical, angiographic and procedural outcome. Circulation 1992;19:1372-9.

48. Isner J, Brinker JA, Gottlieb RS, Leya F, Masden RR, Shani J, Kearney M, Topol EJ. Coronary thrombus: clinical features and angiographic diagnosis in 370 patients treated by directional coronary atherectomy [Abstract]. Circulation 1992;86:I-648.

49. Escaned J, Violaris A, de Jong M, Umans V, de Feyter PJ, Serruys PW. A biologic paradox of restenosis after directional coronary atherectomy: enhanced smooth muscle cell outgrowth and high cellularity of retrieved specimens is associated with less luminal loss [Abstract]. Circulation 1993;88:I-651.

50. Ip JH, Fuster V, Badimon L, Badimon J, Taubman MB, Chesebro JH. Syndromes of accelerated atherosclerosis: role of vascular injury and smooth muscle cell proliferation. J Am Coll Cardiol 1990;15:1667-87.

51. van Beusekom HMM, van der Giessen WJ, van Suylen RJ, Bos E, Bosman FT, Serruys PW. Histology after stenting of human saphenous vein bypass grafts: observations from surgically excised grafts 3 to 320 days after stent implantation. J Am Coll Cardiol 1993;21:45-55.

52. Schwartz RS, Murphy JG, Edwards WD, Camrud AR, Vlietstra RE, Holmes DR. Restenosis after balloon angioplasty. A practical proliferative model in porcine coronary arteries. Circulation 1990;82:2190-200.

53. Schwartz RS, Huber KC, Murphy JG, Edwards WD, Cornrud AR, Vliestra RE, Holmes DR. Restenosis and the proportional neointimal response to coronary artery injury. J Am Coll Cardiol 1992;19:267-75.

54. Schwartz RS, Koval TM, Edwards WD, Camrud AR, Bailey KR, Browne K, Vliestra RE, Holmes DR. Effect of external beam irradiation on neointimal hyperplasia after experimental coronary artery injury. J Am Coll Cardiol 1992;19:1106-14 